\title{
Congenital Cytomegalovirus Infection As Lissencephaly - A Case Report
}

\author{
GOPEN KUMAR KUNDU ${ }^{1}$, MOHSINAAKHTER ${ }^{2}$, SHAHEEN AKHTER ${ }^{3}$, MD. MIZANUR RAHMAN ${ }^{3}$
}

\section{Introduction:}

Human cytomegalovirus is 1 of 8 human herpes viruses. Congenital cytomegalovirus infection is a leading cause of intrauterine infection and brain damage in children. ${ }^{1-3}$ Primary infection occurs in as many as $2.2 \%$ of pregnant women ${ }^{4}$ and serologic or culture evidence of intrauterine CMV infection has been reported in $0.2-2.2 \%$ of all live-born neonates. ${ }^{5}$ Among infected neonates, 90-95\% are asymptomatic at birth, but almost 30\% develop late complications in the 1st year of life. ${ }^{5}$ Fetal infection results from transmission of the virus across the pla-centa and is particularly common in women who experience primary infection during pregnancy. ${ }^{6}$ According to two large systematic literature reviews performed in 2007 examining the epidemiology and outcome of congenital $\mathrm{CMV}$ infection, the prevalence of infection at birth was $0.6 \%-0.7 \%$ in industrialized countries and among those with congenital infection, $11 \%-13 \%$ of patients were symptomatic. ${ }^{7,8}$ Neurologic findings of congenital CMV infection include intracranial calcification, migrational abnormalities, cerebral and cerebellar volume loss, ventriculomegaly, and white matter disease. Lissencephaly, pachygyria, and diffuse or focal polymicrogyria are the most common migrational abnormalities. Lissencephaly is a congenital defect in neuronal migration resulting in a malformation of the brain in which the surface of the brain is devoid of gyri and sulci. Among the various causes of lissencephaly, gestational insults by infection during pregnancy play an important role, particularly by cytomegalovirus. The presence of intracranial calcification in CMV infection-associated lissencephaly is important because in these patients - unlike those with other types of lissencephaly So this lissencephaly is not associated with underlying genetic abnormalities or others. Here we report a case of congenital CMV infection associated with lissencephaly.

1. Assistant Professor, Department of Paediatric, Neurology, BSMMU, Dhaka

2. Resident, Department of Paediatric, BSMMU, Dhaka

3. Professor, Department of Paediatric Neurology, BSMMU, Dhaka

Correspondence: Dr. Gopen Kumar Kundu, Asstt Professor, Paediatric Neurology, BSMMU, Dhaka. Email: gopen.kundu@ gmail.com

\section{Case Report:}

A 7 months old male baby 3 rd issue of nonconsanguineous parents admitted in paediatric neurology ward of BSMMU with repeated convulsion since 1 months of age. Convulsion was generalized tonic-clonic and persist about 2-3 minutes, occurred 10-20 times a day, not associated with fever or post ictal drowsiness. Mother was 25 years old, $4^{\text {th }}$ gravida, para 2+1(abortion) and had an uneventful antenatal period. The baby was delivered at term at home by pervaginally with birth weight $2000 \mathrm{gm}$. After delivery he required hospitalization due to severe perinatal asphyxia with SGA. He also developed hyperbilirubinaemia and was treated by phototherapy in his postnatal period. He developed repeated convulsion since one month his age and was not growing well. He had not achieved neck control \& social smile yet.

He has been suffering from recurrent attacks of respiratory tract infection since birth and congenital heart disease, atrial septal defect was detected by echocardiogram at the age of five month. Since then he has been treated with oral digoxin and diuretics.

There was no history of head injury, unconsciousness, fever, rash, vomiting, feeding difficulties or any seizure disorder in his family. For this illness he was treated with oral phenobarbitone for last 4 months in adequate dose without significant improvement.

On examination baby was alert but facial dysmorphism present - he had medial epicanthic folds and prominent upper lip.There was backward bending of the neck and trunk, and extended lower limbs. He was moderately pale, vital parameters were within normal range. On anthropometry: Length- $60 \mathrm{~cm}$ ( LAZ: -1), Weight - $5 \mathrm{~kg}$ (WAZ: -5) OFC : $36.5 \mathrm{~cm}$ (SD -3.4). Eye examination revealed nystagmas present on both eyes, on fundoscopy old vitreous hemorrhage in right eye with normal fundi. Motor system examination revealed hypertonia and exaggerated deep reflexes in both upper and lower limbs. Other cranial nerves are intact. There was a systolic murmur (grade 3/6) best heard in left parasternal area. Liver was moderately enlarged $(5 \mathrm{~cm})$. Spleen was mildly enlarged $(2 \mathrm{~cm})$ 


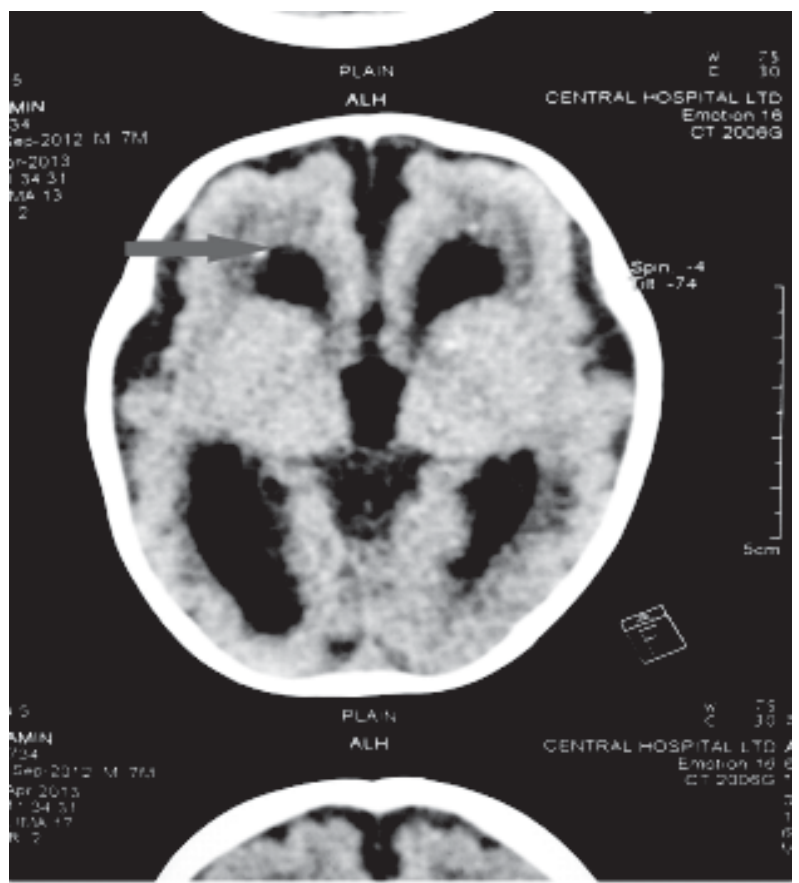

-ıg-1: C' s scan shows ventrıcular dılatatıon, periventricular calcification(arrow) and lissencephaly.

from left costal margin. Developmental assessment showed his social smile is absent, neck control not achieved yet, hearing is impaired, no bubbling, but he can fix gaze and follow an object.

His Ultrasound of brain showed cerebral sulci are poorly defined, lateral ventricles are moderately and symmetrically dilated, calcifications are seen around the lateral ventricles and impression is cytomegalovirus infection. CT Scan of brain showed moderate generalized cerebral cortical atrophy, ventriculomegaly, periventricular calcification and lissencephaly. Baseline blood picture, Urinalysis, blood suger, S.electrolyte, liver and renal function test were normal. Anti CMV antibody (both IgG and IgM) and CMV DNA were positive. Finally the case was diagnosed as cytomegalovirus infection with Lissencephaly with epilepsy. This patient was treated symptomatically by muliple antiepileptic drugs to control seizure and ultimately discharged by proper counseling.

\section{Discussion:}

Lissencephaly, first described by Owen in 1868, means "smooth brain" to describe the gross appearance of the brain. It is a developmental disorder of brain characterized by the lack of normal convolutions and is caused by a defective neuronal migration, which

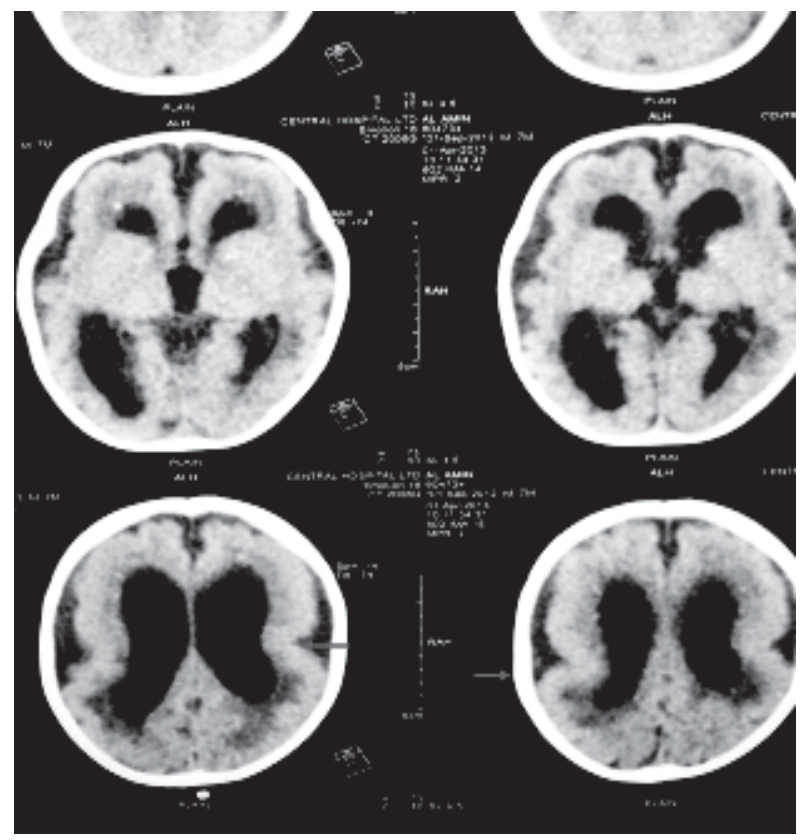

Fig-2: CT scan of brain showed ventricular dilatation(Left arrow), periventricular calcification and lissencephaly (figure of 8-right arrow).

usually occurs between 12- and 16-week-gestation. A variety of migrational abnormalities have been reported in patients with congenital CMV infection, and such abnormalities may be present in as many as $10 \%$ of patients. ${ }^{9}$ Schizencephaly is rare, and cortical dysplasia was described in one patient with congenital CMV infection and concomitant white matter disease. ${ }^{10}$ The other features to suggest CMV infection includes abnormal ventricular signals, intraparenchymal echogenic foci, intra-ventricular adhesions, ventriculomegaly, altered sulcation and gyral pattern and cerebellar anomalies. .

Lissencephaly may be caused by intra-uterine viral infection and insufficient blood supply to the fetal brain in early pregnancy or as a genetic disorder. Among the viral infections, CMV is a very important etiological factor in the causation of lissencephaly. Other causes of central nervous system infections are toxoplasmosis, rubella, herpes simplex, human immunodeficiency virus and syphilis. ${ }^{11} \mathrm{CMV}$ has a particular affinity for the developing germinal matrix of the brain, but it can infect other organs, too. The severity of the brain changes is directly related to the gestational age of the fetus at the time of infection. Early infection leads to more severe migrational and developmental anomalies. Early second trimester infection leads to complete lissencephaly, while late 
second trimester infection causes polymicrogyria anomalies. ${ }^{12}$ Twickler reported the antenatal sonographic findings of cerebral ventriculomegaly and decreased head circumference in two cases, secondary to CMV infection. ${ }^{13}$ Extensive literature search did not reveal any definite epidemiological data as regards the incidence rate of CMV with lissencephaly. CT scan of the brain showed atrophy, ventricular dilatation and parenchymal calcification. MRI findings include migrational anomalies like lissencephaly and polymicrogyria, encephalomalacia with non-specific ventricular enlargement, prominent sulci, subependymal paraventricular cysts and calcifications. ${ }^{14}$ In our indexed case CT of scan brain showed atrophy, ventricular dilatation, parenchymal calcification and lissencephaly.

Cytomegalovirus is diagnosed by other laboratory parameters, which can yield positive serum titers of CMV-specific immunoglobulin M. ${ }^{15}$ CMV DNA can be detected in the cerebrospinal fluid of the patients affected by lissencephaly. In Our patient anti CMV antibody titre was positive. Kohyama et al. studied the involvement of human CMV infections in conditions of neurological impairment in 45 neurologically affected children aged 1 month to 17 years by means of polymerase chain reactions. ${ }^{16}$ Several serologic assays are used to detect the CMV-specific IgM antibodies both in the whole serum and serum fractions obtained by sucrose density gradient centrifugation or column chromatography. Detection and quantification of CMV DNA in blood can be achieved by PCR and hybridization technique. In our patient anti CMV antibody titre was positive and CMV DNA in blood was also positive.

Currently, there is no cure for lissencephaly. Treatment of individual depends on the manifesting symptoms, like anti-convulsant drug therapy for the treatment of seizures. Muscle relaxants may be useful for the symptoms of increased tone. An accurate diagnosis of lissencephaly and CMV infection is mandatory as appropriate preventive measures may be instituted in high-risk pregnancies.

This case has been reviewed to highlight the causal relationship of CMV and lissencephaly.

\section{References:}

1. Demmler GJ, Infectious Diseases Society of America and Centers for Disease Control. Summary of a workshop on surveillance for congenital cytomegalovirus disease. Rev Infect Dis 1991; 13: 315-29

2. Istas AS, Demmler GJ, Dobbins JG, Stewart JA. Surveillance for congenital cytomegalovirus disease: a report from the National Congenital Cytomegalovirus Disease Registry. Clin Infect Dis 1995; 20:665-70.

3. Uziel Y, Shahar G, Regev R, Dolfin Z. CMV infections in the mother and newborn. Harefuah 1991;120:536-39.

4. Yow MD, Williamson DW, Leeds LJ, at al. Epidemiologic characteristics of cytomegalovirus infection in mothers and their infants. $A m \mathrm{~J}$ Obstet Gynecol 1988;158:1189-95.

5. Stagno S, Pass RF, Cloud G, et al. Primary cytomegalovirus infection in pregnancy: incidence, transmission to fetus, and clinical outcome. JAMA 1986; 256: 1904-08

6. Griffiths PD, Emery VC, Milne R. Cytomegalovirus. In: Richman DD, Whitley RJ, Hayden FG, eds. Clini-cal virology. 3rd ed. Washington, DC: ASM Press, 2009.

7. Dollard SC, Grosse SD, Ross DS. New estimates of the prevalence of neurological and sensory sequelae and mortality associated with congenital cyto-megalovirus infection. Rev Med Virol 2007; 17(5): 355-63.

8. Kenneson A, Cannon MJ. Review and metaanalysis of the epidemiology of congenital cytomegalovirus (CMV) infection. Rev Med Virol 2007;17(4): 253-76.

9. van der Knaap MS, Vermeulen G, Barkhof F, Hart AAM, Loeber JG, Weel JFL. Pattern of white matter abnormalities at MR imaging: use of polymerase chain reaction testing of Guthrie cards to link pattern with congenital cytomegalovirus infection. Radiol-ogy 2004; 230: 529-36

10. Zucca C, Binda S, Borgatti R, et al. Retrospective diagnosis of congenital cytomegalovirus infection and cortical maldevelopment. Neurology 2003; 61: 710-12.

11. de Rijk-van Andel JF, Art WF, Hofman A, Staal A, Niermeijer MF. Epidemiology of lissencephaly type I. Neuroepidemiology 1991; 10: 200-4. 
12. Malinger G, Lev D, Zahalka N, Ben Aroia Z, Watemberg $\mathrm{N}$, Kidron $\mathrm{D}$, et al. Fetal cytomegalovirus infection of the brain: The spectrum of sonographic findings. Am J Neuropathol 2003; 24: 28-32.

13. Twickler DM, Perlman J, Maberry MC. Congenital cytomegalovirus infection presenting as a cerebral ventriculomegaly on antenatal sonography. Am J Perinatol 1993; 10: 404-6.

14. Alvarez A, Seara MJ, Linares M, Villalon J. Unusual manifestations of postnatally acquired cytomegalovirus infections: Finding on CT and MR. Pediatr Radiol 1996; 26: 772-4.

15. Donnor C, Liesnord C, Content J. Prenatal diagnosis of 52 pregnancies at risk for congenital cytomegalovirus infection. Obstet Gynecol 1993; 82: 481-6.

16. Kohyama J, Kajiwara M, Shimohira M, Iwakawa Y, Okawa $\mathrm{H}$. Human cytomegalovirus DNA in cerebrospinal fluid. Arch Dis Child 1994; 71: 414-18. 